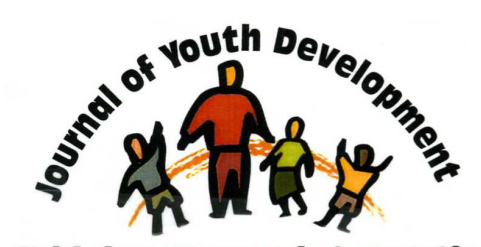

Bridging Research \& Practice

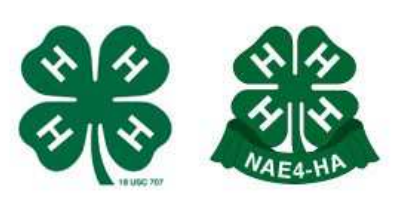

\title{
Relationships Matter: A Mixed-Methods Evaluation of Youth and Adults Working Together as Partners
}

Kenneth R. Jones

Assistant Professor

Youth Development Specialist

University of Kentucky

Lexington, $\mathrm{KY}$

kenrjones@uky.edu 


\title{
JOURNAL OF YOUTH DEVELOPMENT bridging research and practice
}

\section{Relationships Matter: \\ A Mixed-Methods Evaluation of \\ Youth and Adults Working Together as Partners}

Kenneth R. Jones

University of Kentucky

\begin{abstract}
Highlights of a multi-method research study conducted to understand the perceptions and experiences of youth and adults working together within communities are shared in this article. The results revealed that the most positive youth-adult relationship experiences were those with supportive adults willing to share power with youth, those instituting youth-led endeavors where young people were allowed to demonstrate high levels of involvement and responsibility, and those involving participants who had previously worked as a community partner. Participants in Youth-Led Collaborations were more positive toward their experiences than those in Adult-Led Collaborations and YouthAdult Partnerships. Also, participants in relationships located in rural areas indicated more positive experiences than those in urban areas. In addition, the critical elements of various youth-adult relationships were also underscored, thus identifying characteristics that have significant importance in nurturing interactions between young people and positive adults.
\end{abstract}

\section{Introduction}

Researchers and practitioners alike are seeking ways to ensure that young people are exposed to all the essentials necessary for matriculation from childhood to competent, responsible adulthood. Scholars have reported that caring adults who are committed to the betterment of youth are a vital entity in a young person's life (Eccles \& Gootman, 2002; Grossman \& Johnson, 1999; Villarruel, Perkins, Borden, \& Keith, 2003). However, the challenge persists in getting youth and adults to connect with one another and engage in purposeful activities. This article 
highlights the findings of a multi-method research study conducted to understand the contextual differences that often occur among youth-adult relationships. The author presents the perceptions and experiences of both youth and adults working together on community projects.

\section{Theoretical Framework}

A major barrier toward community engagement stems from the impact negative perceptions have on adults and young people (Gilliam \& Bales, 2001; Guzman, Lippman, Moore, \& O'Hare, 2003). Camino (2000) reported that these preconceived stereotypes often pose an impasse to thriving relationships because there is opposition to both parties' willingness to share power. Studies have reported adults' perceptions of youth as being unaware of major trends in youth development (Males, 1999; Lee, Farrell \& Link 2004; Rennekamp, 1993). Furthermore, the experiences of adults when they were young are also reactants to fostering positive or negative perceptions. Adults having to recall undesirable interactions with parents, other family members and teachers often cause painful memories to resurface (Atwater, 1983; Galbo, 1983; Scheer \& Unger, 1995).

In turn, Lynch and Cicchetti (1997) reported that youth perceptions of their relationship with peers were more positive than those with adults. Such negative experiences may cause youth to become reluctant to serve in a capacity where they do not feel welcomed. Many adults miss the fact that youth bring first-hand knowledge and concerns that are not accessible to adults. Youth and adults can learn skills from one another (Zeldin, McDaniel, Topitzes, \& Calvert, 2000) through positive experiences.

Kolb (1984) defined learning "as the process whereby knowledge is created through the transformation of experiences" (p. 38). Mezirow (1997) described transformative learning as individuals allowing their experiences to change their frame of reference by considering new ways of thinking. This correlates to Smith's (1991) proposed attributes of the ideal learner being active and continually reflective on outcomes. Youth-adult partnering can serve as a medium to learn and critically reflect on viewpoints that are most efficient in attaining community empowerment. In essence, partnering may provide opportunities for youth and adults to become immersed in social and cultural experiences leading to positive forms of mutual learning.

Experience is recognized as a highly valuable resource and a defining trait in the learning process (Dewey, 1938; Knowles, 1980; Lewin, 1948; Lindeman, 1961; Mayo, 2000). Youth development researchers (Camino \& Zeldin, 2003; Flanagan \& Faison, 2001; Perkins, Borden, \& Villarruel, 2001) have indicated that youth can gain valuable social leadership skills when fully engaged in experiential learning processes, such as those occurring when working in their communities. These experiences provide reflection-on-action (Merriam \& Cafferella, 1999) that may be associated with responsible, civic-mindedness as youth approach adulthood. Hence, the impact of real-life experiences constitutes a degree of learning by doing, regardless of age.

\section{Purpose and Objectives}

The purpose of this study was to examine the perceptions and experiences of youth and adults engaged in various types of youth-adult relationships involving community projects. The objectives of the study were to:

(1) examine perceptions of individuals engaged in youth-adult relationships at the community level; 
(2) examine experiences of youth and adults working together as partners; and

(3) identify unique characteristics of different types of youth-adult relationships.

\section{Methods and Procedures}

This study included a convenience sample (Patton, 1990) of youth and adults who participated in the Engaging Youth, Serving Community (EYSC) Initiative (see http://www.fourhcounciledu/RuralYouthDevProgram.aspx ) in the Northeastern (U.S.) Region. The Initiative, administered by the USDA/Cooperative State Research, Education and Extension Service (CSREES) and the National 4-H Council, provided rural youth with enhanced opportunities to partner with adults to address local issues. Youth and adults worked together on community service projects that sought to improve levels of youth leadership and adult support.

States participating in the EYSC Initiative were: Connecticut, Delaware, Maine, Massachusetts, New Hampshire, New Jersey, New York, Pennsylvania, Vermont, and West Virginia. In addition, participants from the Philadelphia area were recruited for this project to provide an urban sample. Two groups (i.e., Camden, NJ and Haddington, PA [a section of West Philadelphia]) were selected because they were in the beginning stages of bringing youth and adults together to promote community change.

A concurrent triangulation design utilizing both quantitative and qualitative data sources was employed. Quantitative data were analyzed using descriptive statistics, t-tests, and analyses of variance (ANOVA). The data were collected from 108 participants in groups from 10 states and 12 communities (10 rural, two urban) using the Involvement and Interaction Rating Scale (Jones \& Perkins, 2005), which measured participants' perceptions of their experiences working together. The rating scale measured three constructs: youth involvement, adult involvement, and youth-adult interaction. Qualitative data were collected using observations, semi-structured interviews, and multiple-case study analyses.

Post-hoc reliability of the rating scale yielded an overall Cronbach's of .94. Reliability coefficients for each of the three constructs of the rating scale were: .83 (Youth Involvement), .84 (Adult Involvement), and .87 (Youth-Adult Interaction). Inter-coder agreement was used to determine the validity of the researcher's selecting of themes for the interviewed participants' responses. Inter-rater reliability was also utilized to examine correlations between the researcher's ratings and participants' ratings of their experiences (Kappa $=.79$ ).

The study targeted five types of groups located along the Youth-Adult Relationships Continuum. The five relationships are listed in Table 1. 


\section{Table 1}

The Five Types of Youth-Adult Relationships

\begin{tabular}{|l|l|}
\hline Adult-Centered Leadership & $\begin{array}{l}\text { Programs that are conceived and driven completely } \\
\text { by adults, without employing any youth decision- } \\
\text { making }\end{array}$ \\
\hline Adult-Led Collaboration & $\begin{array}{l}\text { Programs or situations where adults provide } \\
\text { guidance for youth; youth have some input in } \\
\text { decision making, but adults make final decisions }\end{array}$ \\
\hline Youth-Adult Partnership & $\begin{array}{l}\text { Point of stasis where youth and adults have equal } \\
\text { chances in utilizing skills, decision-making, mutual } \\
\text { learning and independently carrying out tasks to } \\
\text { reach common goals }\end{array}$ \\
\hline Youth-Led Collaboration & $\begin{array}{l}\text { Youth primarily generate ideas and make decisions } \\
\text { while adults typically provide assistance when } \\
\text { needed }\end{array}$ \\
\hline Youth-Centered Leadership & $\begin{array}{l}\text { Programs or activities led exclusively by youth, with } \\
\text { little or no adult involvement }\end{array}$ \\
\hline
\end{tabular}

Note. For more specific details, see Jones (2004). An assessment of perceptions and

experiences in community-based youth-adult relationships. Unpublished doctoral dissertation, The Pennsylvania State University, University Park, PA.

Adult leaders of the participating groups were asked to indicate the type of relationship of their groups based on the Youth-Adult Relationships Continuum presented in Figure 1. The adult leaders were provided detailed descriptions of each relationship to assist them in accurately classifying their groups. As a result, five (5) groups were classified as Adult-Led Collaborations, five (5) as Youth-Adult Partnerships and two (2) as Youth-Led Collaborations. However, this does not confirm that these three are the only relationships existing within communities. Despite Adult-Centered and Youth-Centered Leadership relationships not being part of these analyses, there is evidence that they are prevalent at the community level.

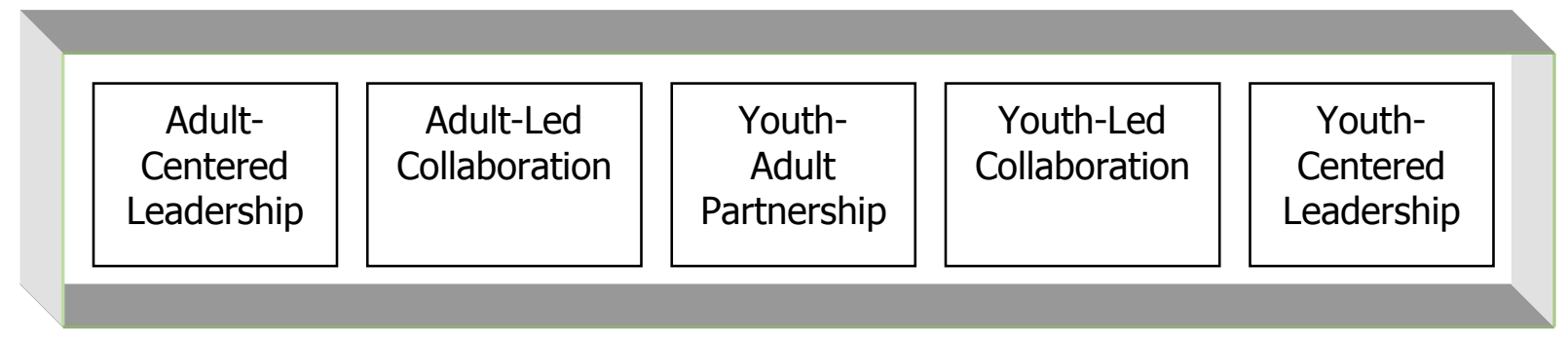

Figure 1. Youth-Adult Relationships Continuum 


\section{Findings}

The demographic characteristics presented in Table 2 include the youth and adults who participated in this study. These characteristics are described to provide contextual information on the findings that were revealed through the analyses.

Table 2

Demographic Characteristics of Youth and Adult Participants $(\underline{\underline{N}}=108)$

\begin{tabular}{|c|c|c|}
\hline Demographic Variable & $f$ & $\%$ \\
\hline $\begin{array}{c}\text { Age Classification } \\
\text { Youth (13-18) }\end{array}$ & 51 \\
Adult (19 and older) & 55 & 49 \\
\hline Gender Fouth & 53 & \\
Adults & 33 & 30.6 \\
Youth & 42 & 38.9 \\
Adults & & \\
Male & 22 & 20.4 \\
Yomale & 11 & 10.1 \\
Rural/farm & 44 & 40.8 \\
Suburban & 17 & 15.7 \\
Urban/City & 47 & 43.5 \\
\hline Description of Community & 39 & 36.1 \\
Yes & 69 & 63.9 \\
\hline No & & \\
\hline
\end{tabular}

\section{Perceptions of Participants}

In regard to influences of the type of relationships, an analysis of variance determined a statistically significant difference between participants in Adult-Led Collaborations $(M=6.74)$ and those in Youth-Led Collaborations $(M=8.00)$, with youth involvement being higher in the latter. Mean scores indicated that participants in Youth-Led Collaborations had more positive perceptions of the level of adult involvement and youth-adult interaction within their groups than participants in Adult-Led Collaborations and Youth-Adult Partnerships (Table 3). 
Table 3

Participants' Youth Involvement, Adult Involvement and Youth-Adult Interaction Perceptions by Relationship Category

\begin{tabular}{|c|c|c|c|c|c|c|c|c|}
\hline \multirow[t]{2}{*}{ Perceptions } & \multicolumn{2}{|c|}{$\begin{array}{c}\text { Adult-Led } \\
\text { Collaboration }\end{array}$} & \multicolumn{2}{|c|}{$\begin{array}{l}\text { Youth-Adult } \\
\text { Partnership }\end{array}$} & \multicolumn{2}{|c|}{$\begin{array}{l}\text { Youth-Led } \\
\text { Collaboration }\end{array}$} & \multirow[t]{2}{*}{$F$} & \multirow[t]{2}{*}{$p$} \\
\hline & Mean & $S D$ & Mean & $S D$ & Mean & $S D$ & & \\
\hline Youth Involvement & $\begin{array}{c}6.74 * \\
(50)\end{array}$ & 1.21 & $\begin{array}{l}7.34 \\
(27)\end{array}$ & 1.56 & $\begin{array}{c}8.00^{*} \\
(15)\end{array}$ & 1.11 & 5.92 & $.004 * *$ \\
\hline Adult Involvement & $\begin{array}{l}7.42 \\
(53)\end{array}$ & 1.66 & $\begin{array}{l}7.43 \\
(29)\end{array}$ & 1.72 & $\begin{array}{l}8.06 \\
(17)\end{array}$ & 1.25 & 1.09 & .341 \\
\hline Youth-Adult Interaction & $\begin{array}{l}6.77 \\
(49)\end{array}$ & 1.37 & $\begin{array}{l}7.00 \\
(29)\end{array}$ & 1.39 & $\begin{array}{l}7.53 \\
\text { (15) }\end{array}$ & 1.03 & 1.87 & .160 \\
\hline
\end{tabular}

Note. These relationship categories were based on the adult leaders' classification of their groups. Scale ranged from 1-10. * Mean values were statistically significant only between individuals in Adult-Led and Youth-Led Collaborations. $* * \underline{p}<.01$.

An analysis of variance found significant differences between the perceptions of adults in YouthAdult Partnerships and Adult-Led Collaborations (Table 4). Adults in Youth-Adult Partnerships had more positive perceptions of youth involvement $(M=7.85)$ than adults in Adult-Led Collaborations $(M=6.64)$. Also, adults in Youth-Adult Partnerships $(M=7.69)$ had more positive perceptions of youth-adult interaction than those adults in Adult-Led Collaborations ( $M=6.63)$. Adults in Youth-Led Collaborations were the most positive, although there was no revealed significant difference.

\section{Table 4}

Adult Participants' Youth Involvement, Adult Involvement and Youth-Adult Interaction Perceptions by Relationship Category

\begin{tabular}{|l|c|c|c|c|c|c|c|c|}
\hline & \multicolumn{2}{|c|}{$\begin{array}{c}\text { Adult-Led } \\
\text { Collaboration }\end{array}$} & \multicolumn{2}{|c|}{$\begin{array}{c}\text { Youth-Adult } \\
\text { Partnership }\end{array}$} & \multicolumn{2}{c|}{$\begin{array}{c}\text { Youth-Led } \\
\text { Collaboration }\end{array}$} & $F$ & $p$ \\
\hline & Mean & $S D$ & Mean & $S D$ & Mean & $S D$ & & \\
\hline Youth Involvement & $6.64^{*}$ & 1.11 & $7.85^{*}$ & 1.43 & 8.00 & 1.44 & 5.34 & $.009^{* *}$ \\
& $(23)$ & & $(15)$ & & $(6)$ & & & \\
\hline Adult Involvement & 7.53 & 1.31 & 8.06 & 1.46 & 8.14 & .98 & 1.07 & .351 \\
& $(26)$ & & $(16)$ & & $(7)$ & & & \\
\hline Youth-Adult Interaction & $6.63^{*}$ & 1.02 & $7.69 *$ & 1.25 & 7.84 & .56 & 5.75 & $.006^{* *}$ \\
& $(21)$ & & $(16)$ & & $(6)$ & & & \\
\hline
\end{tabular}

Note. Scale ranged from 1-10. * Mean values were statistically significant only between individuals in adult-led collaborations and youth-adult partnerships. $* * \underline{p}<.01$. 
Groups from rural areas consisted primarily of participants who were significantly more positive $(M=7.50)$ toward youth involvement than those participants from urban areas $(M=6.67)$. Although there was no significance in relation to the constructs, adult involvement and youthadult interaction, it is of interest to note that participants in rural areas had more positive ratings on these areas as well (Table 5).

Table 5

Youth Involvement, Adult Involvement, and Youth-Adult Interaction Perceptions by Place of Residence

\begin{tabular}{|l|c|c|c|c|c|c|c|c|}
\hline & \multicolumn{2}{|c|}{ Rural } & \multicolumn{2}{c|}{ Suburban } & \multicolumn{2}{c|}{ Urban } & $\mathrm{F}$ & $\mathrm{p}$ \\
\hline & Mean & $S D$ & Mean & $S D$ & Mean & $S D$ & & \\
\hline Youth Involvement & $7.50^{*}$ & 1.32 & 7.16 & 1.49 & $6.67^{*}$ & 1.29 & 3.78 & $.027^{* *}$ \\
& $(41)$ & & $(15)$ & & $(36)$ & & & \\
\hline Adult Involvement & 7.75 & 1.43 & 7.59 & 1.71 & 7.28 & 1.77 & .879 & .418 \\
& $(42)$ & & $(17)$ & & $(40)$ & & & \\
\hline Youth-Adult Interaction & 7.30 & 1.18 & 6.83 & 1.33 & 6.59 & 1.46 & 2.98 & .056 \\
& $(44)$ & & $(13)$ & & $(36)$ & & & \\
\hline
\end{tabular}

Note. Scale ranged from 1-10. * Mean values were statistically significant only between rural and urban groups. $* * \underline{\mathrm{p}}<.05$.

Although adults provided more positive ratings than youth towards the constructs (i.e., youth involvement, adult involvement and youth-adult interaction), an independent t-test found no significant differences between youth and adult perceptions on these constructs. Also, there were no statistically significant differences between youth participants across each of the three youth-adult relationships.

\section{Experiences of Youth and Adult Participants}

Four groups were selected, based on their location and progress with their community project, for observations and interviews to assess the participants' experiences of working together as partners. All of the adult participants had worked with youth at some point in time and were accepting of youth leadership. However, nearly all ( 8 of 9$)$ of the youth who were interviewed noted that despite negative experiences (e.g., adults "taking over"), they encountered adults who were very supportive. All 18 of the interviewed participants (nine youth and nine adults) indicated a willingness to participate in a similar endeavor in the future.

In this study, participants seemed cautious in openly expressing themselves during meetings. The researcher observed youth, in trainings with adults, as being very reluctant to participate fully in group discussions. In one group, the youth often seemed intimidated by adults and appeared to act as though their responses would not be taken seriously. On the other hand, some adults were also hesitant to share their perspectives because they did not want to offend the youth. Obviously, a comfort level was not established with peers of the same or similar ages, which may have caused some discomfort when participants came together for a joint training. 
Youth in Adult-Led Collaborations appeared to need more time to reach the point of actually seeing themselves as leaders, while adults needed to develop and utilize strategies that encouraged youth participation. Within the three Adult-Led Collaborations that were observed, the youth appeared ill-prepared for the expected level of responsibility and decision-making and therefore were dependent on adult guidance. The adults, in contrast, were disturbed by not being able to successfully perpetuate youth voice (i.e., opinions, input) and leadership. Young people in the Youth-Led Collaboration demonstrated assertiveness, leadership and a fervency to take on responsibilities. This observed relationship displayed a youth-driven model where the youth had ownership in program activities and felt empowered serving in meaningful decision-making roles. The adults were willing to take on a more supportive role, thus relinquishing some power to young people, while encouraging youth leadership.

\section{Characteristics of Various Youth-Adult Relationships}

Several characteristics surfaced through observations and the interviews as critical elements of youth-adult relationships. Those elements were identified as adult support, civility/mutual respect, community obligation, decision-making, mutual learning, youth responsibility, and youth voice. Table 6 includes the critical elements based on data collected from all participants using the Involvement and Interaction Rating Scale, observations of four selected groups, and interviews of nine youth and nine adult participants.

\section{Table 6}

Characteristics of Adult-Led Collaborations (Adult Driven) vs. Youth-Led Collaborations (Youth-Driven)

\begin{tabular}{|l|l|}
\hline \multicolumn{1}{|c|}{ Adult-Led Collaborations } & \multicolumn{1}{c|}{ Youth-Led Collaborations } \\
High levels of adult involvement/support & High levels of adult involvement/support \\
Moderate level of community obligation ${ }^{1}$ & High levels of civility/mutual respect \\
Low youth decision-making & High level of youth decision-making \\
Low youth responsibility & High youth responsibility \\
Little, if any, mutual learning & Little, if any, mutual learning \\
Youth ideas considered by adults & Youth ideas highly valued by adults \\
Youth voice ${ }^{2}$ solicited/considered by adults & Youth voice ${ }^{2}$ solicited/utilized by adults \\
\hline
\end{tabular}

Note. " 1 " = Community Obligation references youth and adults committed to making an impact on the entire community (level determined by participants' enthusiasm towards community and the scope of their project); "2" = Youth Voice refers to youth sharing opinions and providing input during group discussion.

The above-listed elements may help determine which relationship types are most effective and appropriate for certain community projects. Though some characteristics are more specific to one particular relationship, these critical elements can be implemented within community youth 
programs and other collaborative efforts to ascertain whether young people are receiving the most valuable experiences through participatory learning and positive relationships with adults.

\section{Conclusions and Discussion}

All participants in Youth-Led Collaborations were the most positive toward youth involvement. Perhaps these participants were more positive because of the passion towards their project and the meaningful roles that were afforded to the young people. The adults indicated that they purposely kept their involvement to a minimum in order to maximize youth participation. Given this situation, the youth apparently provided positive ratings of the youth-adult interaction because they had a major role in the project, while the adults were positive towards youth taking on this responsibility and exerting their leadership potential.

Adults in Youth-Adult Partnerships had more positive perceptions than those in Adult-Led Collaborations. One potential reason for this finding may be that the adults in these groups sincerely believed that they had achieved a genuine partnership; therefore, they believed that youth involvement was high and their interactions with young people were authentically positive. However, the youth's views of youth involvement and youth-adult interaction were less buoyant. Instead, they perceived their decision-making roles as minimal, at best, thus indicating that a "partnership" did not fully exist.

Groups in rural areas had more positive perceptions toward youth involvement than those in urban communities. This was due, in part, because the rural groups were targeted specifically for participation in the EYSC initiative and were considered ready for this type of endeavor. Another possible explanation is that the rural sample (unlike the urban groups) involved youth who were involved in 4-H activities for several years prior to this project, and the youth knew the adults involved in their groups.

Observations of group dynamics and interviews of participants were used to assess youth and adult engagement. One weakness reported by adults and youth was that youth voice and decision-making were not always utilized to capacity. While civility/mutual respect was prevalent and youth voice was solicited in both Youth-Led and Adult-Led Collaborations, the level of youth voice was higher, more valued and readily utilized in Youth-Led Collaborations. Considering that adult support was observed as high among all groups, adult practitioners and volunteers may wish to direct their support toward encouraging youth to engage in dialogue, develop critical thinking skills, and decision making skills. For example, involving youth in professional development training components may be a worthy part of a youth organization's mission.

Those youth and adult participants indicating previous involvement in partnerships appeared more comfortable, while those encountering their first youth-adult community project seemed more uneasy. The youth, in particular, appeared intimidated by adults to some degree. Hence, youth-service providers recruiting both experienced adults and experienced youth to work with younger youth and novice adult volunteers may prove beneficial in strengthening youth-adult partnering ventures.

Some elements revealed in this study were apparently unique to specific relationships. For example, mutual learning was not widespread in either type of relationship that was observed and analyzed, yet it has been described as imperative to a true Youth-Adult Partnership (see Camino, 2000). Evidently, a situation where youth and adults equally serve as teachers and 
participatory learners exists when both have the opportunity to utilize their skills and disseminate knowledge to one another. Theoretically, this would most likely occur where youth and adults are contributors as well as receivers in an educative process. Youth-service providers may want to consider the critical elements of various relationships when designing programs to endow young people with the wherewithal to partner with adults.

The projects of each observed group targeted primarily those areas of the community that participants were most familiar with (e.g., schools attended by the youth, facilities utilized by the group on previous occasions), which indicated a moderate level of community obligation. A high level of community obligation would be reflective of a project that is beneficial on a larger scale (i.e., the entire county or multiple schools). In addition, not all participants were as enthusiastic about the project's benefit to the community. For example, based on the author's observations, several youth in the urban groups seemed to have less of a vested interest, due to their project work often taking place in less proverbial neighborhoods.

Youth-serving organizations must began to promote the generation of social capital, particularly in urban areas, that mirrors the stronger community connectedness than may exist in smaller, more rural localities. Larger urban communities often lack the condition where all neighbors know one another. Moreover, intergenerational relationships may decrease negative perceptions toward differences by allowing people to acknowledge and embrace their commonalities (Allport, 1954; Pettigrew, 1998; Swisher \& Whitlock, 2004). Many youth will have their first encounter with a partnering effort at the Adult-Led Collaborative level. Consequently adults must practice more active facilitation and patience in encouraging the youth to arrive at a point where they feel comfortable serving as a full-fledged community partner.

\section{Limitations}

Limitations of this study were as follows:

1. The generalizability of the results does not extend beyond the participants in this sample.

2. The researcher made 2-4 visits to each group. Although points of saturation were reached within the qualitative analyses, a more thorough evaluation of group interaction may have been possible through additional visits.

\section{Recommendations}

It is important that youth programs have an intentional structure that facilitates positive youthadult interaction (Jekielek, Moore, \& Scarupa, 2002). Youth service providers should target adults who bring experience, enthusiasm, comfort in power-sharing and feelings of personal closeness in working with youth (Dubois \& Neville, 1997). Training for adults before and during their work together with youth partners would be helpful, especially for adults who are less skilled. Adults, along with young people who have previous experience, could also benefit from learning new techniques that strengthen relationships. Youth-serving organizations need to ensure that young people have access to a number of caring adults that can serve as mentors, as well as community allies. 


\section{Recommendations for Further Research}

Based on the findings of this study:

1. Researchers should conduct similar studies using a larger sample that includes a broader range of organizations engaged in building youth-adult relationships (and existing within different contexts (e.g., schools, faith-based institutions).

2. Longitudinal studies should be conducted to determine if the perceptions of youth and adults change over time when working together as partners.

3. Integrated qualitative and quantitative procedures are needed to investigate the complexities and dynamics of various types of youth-adult relationships.

4. Future research should consider testing the components of group interaction (i.e., Intergroup Contact Theory; see Allport, 1954)) to examine factors that influence the power dynamics associated with the segregation between youth and adults.

\section{Summary}

The major conclusion drawn from this study is inclusive at best, offering strong evidence for more empirical inquiries. Previous qualitative inquiries providing exploratory research on youthadult relationships and local partnerships have provided a plethora of background information to the theoretical framework of this investigation. Furthermore, this research provides a better understanding of the role and effectiveness of youth-adult interactions in communities. As additional research efforts on the benefits of youth-adult partnerships and other forms of positive relationships are pursued, youth and adults will become more capable of valuing one another and working together on behalf of their communities.

\section{References}

Allport, G. W. (1954). The nature of prejudice. New York, NY: Doubleday Books.

Atwater, E. (1983). Adolescence. Englewood Cliffs, NJ: Prentice-Hall, Inc.

Camino, L. A. (2000). Youth-adult partnerships: Entering new territory in community work and research. Applied Developmental Science, 4, 11-20.

Camino, L., \& Zeldin, S. (2003). From periphery to center: Pathways for youth civic engagement in the day-to-day life of communities. Applied DevelopmentalScience, 4.

Dewey, J. (1938). Experience and education. New York, NY: Touchstone.

Dubois, D. L., \& Neville, H. A. (1997). Youth mentoring: Investigation of relationship characteristics and perceived benefits. Journal of Community Psychology, 25, 227-234.

Eccles, J. S., \& Gootman, J. A. (Eds.). (2002). Community programs to promote youth development. Committee on Community-Level Programs for Youth. Washington, DC: National Academy Press.

Flanagan, C. A. \& Faison, N. (2001). Youth civic development: Implications of research for social policy and programs. (Social Policy Report, 15(1) of the Society for Research in Child Development). Available online at: http://www.srcd.org/sprv15n1.pdf 
Galbo, J. (1983, Summer). Adolescents' perceptions of significant adults. Adolescence. 18, 417427.

Gilliam, F. D., Jr. \& Bales, S. N. (2001, July). Strategic frame analysis: Reframing America's youth. (Social Policy Report, 15(3) of the Society for Research in Child Development). Available online at: http://www.srcd.org/sprv15n3.pdf

Grossman, J. B., \& Johnson, A. (1999, June). Assessing the effectiveness of mentoring programs. In J.B. Grossman, (Ed.), Contemporary issues in mentoring. Public Private Ventures. Available online at: http://www.ppv.org/pdffiles/cimentoring/cim_3.pdf

Guzman, L., Lippman, L., Moore, K. A., \& O'Hare, W. (2003, July). How children are doing: The mismatch between public perception and statistical reality (Research Brief \#2003-

12).Washington, DC: Child Trends.

Jekielek, S. M., Moore, K. A., Hair, E. C., \& Scarupa, H. J. (2002, February). Mentoring: A promising strategy for youth development (research brief).Washington, DC: Child Trends.

Jones, K. R. (2004). An assessment of perceptions and experiences in community-based youthadult relationships. Unpublished doctoral dissertation, The Pennsylvania State University, University Park.

Jones, K.R. \& Perkins, D.F. (2005). Determining the quality of youth-adult relationships within community-based youth programs. Journal of Extension, 43(5). Available online at: http://www.joe.org/joe/2005october/a5.shtml

Kolb, D. A. (1984). Experiential learning: Experience as the source of learning and development. Englewood Cliffs, NJ: Prentice Hall.

Knowles, M. S. (1980). The modern practice of adult education: From pedagogy to androgogy. ( $2^{\text {nd }}$ ed.). New York, NY: Cambridge Books.

Lee, B. A., Farrell, C. R., \& Link, B. G. (2004). Revisiting the contact hypothesis: The case of public exposure to homelessness. American Sociological Review, 69, 40-63.

Lewin, K. (1948). Resolving social conflicts: Selected papers on group dynamics. Lewin, G. W. (Ed). New York, NY: Harper and Row.

Lindeman, E. (1961). The meaning of adult education. New York, NY: Harvest House.

Lynch, M. \& Cicchetti, D. (1997). Children's relationships with adults and peers: An examination of elementary and junior high school students. Journal of School Psychology, 35, 81-100.

Mayo, M. (2000). Learning for active citizenship: Training for and learning from participation in area regeneration. Studies in the Education of Adults, 32, 22-35.

Males, M. (1999). Framing youth: Ten myths about the next generation. Monroe, ME: Common Courage Press. 
Merriam, S. B., \& Caffarella, R. S. (1999). Learning in adulthood: $A$ comprehensive guide ( ${ }^{\text {nd }}$ ed.). San Francisco, CA: Jossey-Bass.

Mezirow, J. (1997). Transformative learning: Theory to practice. In P. Cranton (Ed.), Transformative learning in action: Insights from practice. new directions for adult and continuing education, 74, 5-12, San Francisco, CA: Jossey-Bass.

Patton, M. Q. (1990). Qualitative evaluation and research methods (2 ${ }^{\text {nd }}$ ed.). Newbury Park, CA: Sage.

Perkins, D. F., Borden, L. M., \& Villarruel, F. A. (2001). Community youth development: A partnership for change. School Community Journal, 11, 39-56.

Pettigrew, T. F. (1998). Intergroup contact theory. Annual Review of Psychology, 49, 65-85.

Rennekamp, R. (1993). Double standard for youth involvement. Journal of Extension, 31. Available online at: http://www.joe.org/joe/1993fall/f2.html

Scheer, S. D., \& Unger, D. G. (1995). Parents' perceptions of their adolescence: Implications for parent-youth conflict and family satisfaction. Psychological Reports, 76, 131-136.

Smith, R. M. (1991, April). How people become effective learners. Adult Learning, 2, 11-13.

Swisher, R., \& Whitlock, J. (2004). How neighborhoods matter for youth development. In S. F. Hamilton, \& M. A. Hamilton (Eds.), The youth development handbook: Coming of age in America. Thousand Oaks, CA: Sage.

Villarruel, F. A., Perkins, D. F., Borden, L. M., \& Keith, J. G. (2003). Community youth development: Practice, policy and research. Thousand Oaks, CA: Sage.

Zeldin, S., McDaniel, A., Topitzes, D., \& Calvert, M. (2000). Youth in decision-making: A study on the impact of youth on adults and organizations (Report). Chevy Chase, MD: Innovation Center for Community and Youth Development

(C) Copyright of Journal of Youth Development Bridging Research and Practice. Content may not be copied or emailed to multiple sites or posted to a listserv without copyright holder's express written permission. Contact Editor at: patricia.dawson@oregonstate.edu for details. However, users may print, download or email articles for individual use.

ISSN 2325-4009 (Print); ISSN 2325-4017 (Online) 